Pak. J. Agri. Sci., Vol. 53(1), 257-264; 2016

ISSN (Print) 0552-9034, ISSN (Online) 2076-0906

DOI: $10.21162 / P A K J A S / 16.2887$

http://www.pakjas.com.pk

\title{
CONJUNCTIVE USE OF WATER AND ITS MANAGEMENT FOR ENHANCED PRODUCTIVITY OF MAJOR CROPS ACROSS TERTIARY CANAL IRRIGATION SYSTEM OF INDUS BASIN IN PAKISTAN
}

\author{
Muhammad Usman', Azhar Abbas ${ }^{2,3, *}$ and Zulfiqar Ahmad Saqib ${ }^{4,5^{*}}$ \\ ${ }^{1}$ Institute for Groundwater Management, TU Dresden, Germany ; ${ }^{2}$ Institute of Agricultural and Resource Economics, \\ University of Agriculture, Faisalabad-Pakistan; ${ }^{3}$ Leibniz Centre for Agricultural Landscape Research (ZALF), \\ Eberswalder Straße 84, D-15374, Muencheberg, Germany; ${ }^{4}$ Institute of Soil and Environmental Sciences, University \\ of Agriculture, Faisalabad-38040, Pakistan; ${ }^{5}$ Saline Agriculture Research Centre, University of Agriculture, \\ Faisalababad-38040, Pakistan \\ *Corresponding author's e-mail: azhar.abbas@zalf.de
}

\begin{abstract}
Farmers in Pakistan either rely only on groundwater or manage conjunctive use of surface and groundwater for irrigating crops due to shortage of canal water. Present study was undertaken to find variations in conjunctive water management practices, groundwater productivity and crop profitability in Chuharkana irrigation sub-division in Punjab. Physical and questionnaire based data were collected from 120 farmers using stratified random sampling technique from vicinity of four watercourses of Lagar distributary. Trajectory method was employed to measure tubewells' discharge for evaluating groundwater productivity across watercourse reaches. EC, SAR and RSC were measured to evaluate groundwater quality. Results show prevalence of surface and groundwater use for irrigation. Area under conjunctive use decreased from $76.6 \%$ at head to $46 \%$ at tail due to decreased canal water supply towards tail while area irrigated by groundwater-only increased from $20 \%$ to $54 \%$ across head to tail. Analysis of groundwater samples showed lower quality levels. EC, SAR and RSC ranged between 1.27-1.55 dS m$~ m^{-1}$, 6.39-9.54 (mmol L-1 $)^{1 / 2}$ and 3.75-4.18 $\mathrm{meL}^{-1}$ respectively, with higher values towards tail. Groundwater productivity for wheat was relatively higher at the head, while that of rice did not vary much across watercourse reaches. Conducive soil conditions and more reliance on groundwater for timely irrigation resulted gross margins at the tail.
\end{abstract}

Keywords: Tubewell, canal, irrigation, profitability, crops, Indus

\section{INTRODUCTION}

Water resources in Pakistan face a major stress due to their poor management in terms of storage and application along with increased demand to fulfill food and fibre requirements of rapidly growing population (Tularam and Marchisella, 2014). The per capita water availability has already declined from $5260 \mathrm{~m}^{3}$ in $1951,1700 \mathrm{~m}^{3}$ in $1992,1400 \mathrm{~m}^{3}$ in 2000 and $964 \mathrm{~m}^{3}$ in 2014 due to the combined effect of rising population, decreasing water flow and the reduction in storage capacity (Shabbir et al., 2012; Usman et al., 2015). Nevertheless, there are still some feasible options to increase or at least maintain water supply through its management and governance.

Indus Basin River System is the main source of surface water for agricultural production in Pakistan expanding to 65 percent area of the country (Kazi, 2014). The Indus Basin Irrigation System (IBIS) mainly depends on river flows, about 180 billion $\mathrm{m}^{3}$ of which comes from snow and glacier melts. The total irrigated land in the Indus Basin is 22.86 million hectares (mha) of which 13.92 mha lies in Pakistan (Laghari et al., 2012).
Another important source of water in the Basin is groundwater as the Basin is underlain by a thick alluvial aquifer; covering about 16 mha (Qureshi et al., 2008). Agricultural production depends heavily on the groundwater in addition to the surface water. Groundwater is pumped through tubewells. Installation of tubewells has taken much pace over the last decade as private tubewell density (number of private tubewells per $1000 \mathrm{ha}$ ) has increased from only 1 in 1960 to 32 in 2002 and 54 in 2011 (Bureau of Statistics, 2013; Qureshi et al., 2004). Furthermore, groundwater abstraction has increased exponentially as, for example, from $9 \mathrm{~km}^{3}$ in 1965 to $45 \mathrm{~km}^{3}$ in 2002 (Qureshi et al., 2009; World Bank, 2007). Groundwater pumping is relatively high in Punjab province where most of the irrigated area is located. This increased groundwater pumping takes place both in canal-command areas and noncanal-irrigated areas though it is high-paced in the former. The total irrigated area in Punjab is 14.53 mha, out of which 3.62 mha are irrigated by canals only, whereas 2.95 mha are irrigated exclusively by tubewells. About $54 \%$ of the irrigated area in the province is irrigated both by canals and 
tubewells while rest of the area (0.09 mha) is irrigated by other means (Ahmad, 2007).

Conjunctive mode of irrigation is more common in Punjab as 60 to $65 \%$ of the population of the province is directly or indirectly dependent on groundwater as a supplemental source to augment canal water supplies (Kazmi et al., 2012). Groundwater is the major contributor towards agricultural productivity but minimum efforts are undertaken to ensure its sustainable use. Secondary salinization, increased water table depths and sea water intrusion in the coastal areas of Indus Basin are some of the side effects of excessive groundwater abstraction by private users leading to longterm consequences for crops and soils. Nevertheless, the judicious use of ground and surface water is expected to optimize productivity and equity in the management of both water resources (World Bank, 2006). Moreover, the changes in the management of irrigation practices are associated with potential benefits in terms of income generation and sustainability of water resources in the wake of unreliable surface water supplies (Raza et al., 2010).

Many potential benefits are associated with planned conjunctive use of ground and surface water such as greater social and economic outcomes due to increased water use efficiency (Evans and Evans, 2011). The governments and planners have neglected to discern over the possibilities of sustaining water resources under the wake of increased food and fibre security concerns. Under such a scenario, there is great potential of exploring and disseminating information about the utilization of water resources for efficient management and sustainability of agricultural production through proper policy interventions. Very little is known about the pattern, productivity and governance system pertaining to joint use of ground and surface water in Pakistan generally and in Punjab province, in particular. The present study has been conducted to develop an understanding of patterns in which ground and surface water resources are used for irrigation, their quality across reaches of the tertiary canal irrigation system, their effects on productivity and profitability of crops within Punjab province.

\section{MATERIALS AND METHODS}

Site selection: This study was conducted in Chuharkana irrigation sub-division, lower Chenab canal system in the Rechna Doab sub-basin of IBIS. A multistage stratified random sampling technique was adopted to draw samples. Out of the 28 irrigation sub-divisions in Rechna sub-basin, one sub-division (Chuharkana) was selected at random. Out of the three major canal distributaries in this sub-division, Lagar distributary was selected. At third stage of sampling, four randomly selected villages are Padianwala (7554-R), Bhandoor (10666-R), Sacha Soda (26513-L) and Mailian (32033-L) situated in district Sheikhupura of Punjab province (Fig. 1). The selected area is mainly characterized by rice-wheat cropping system. From each selected village, one tertiary water channel was selected on the basis of its command area. A sample of 30 farmers (10 each at head, middle and tail of each watercourse) was selected thus making total sample size of 120 farmers.

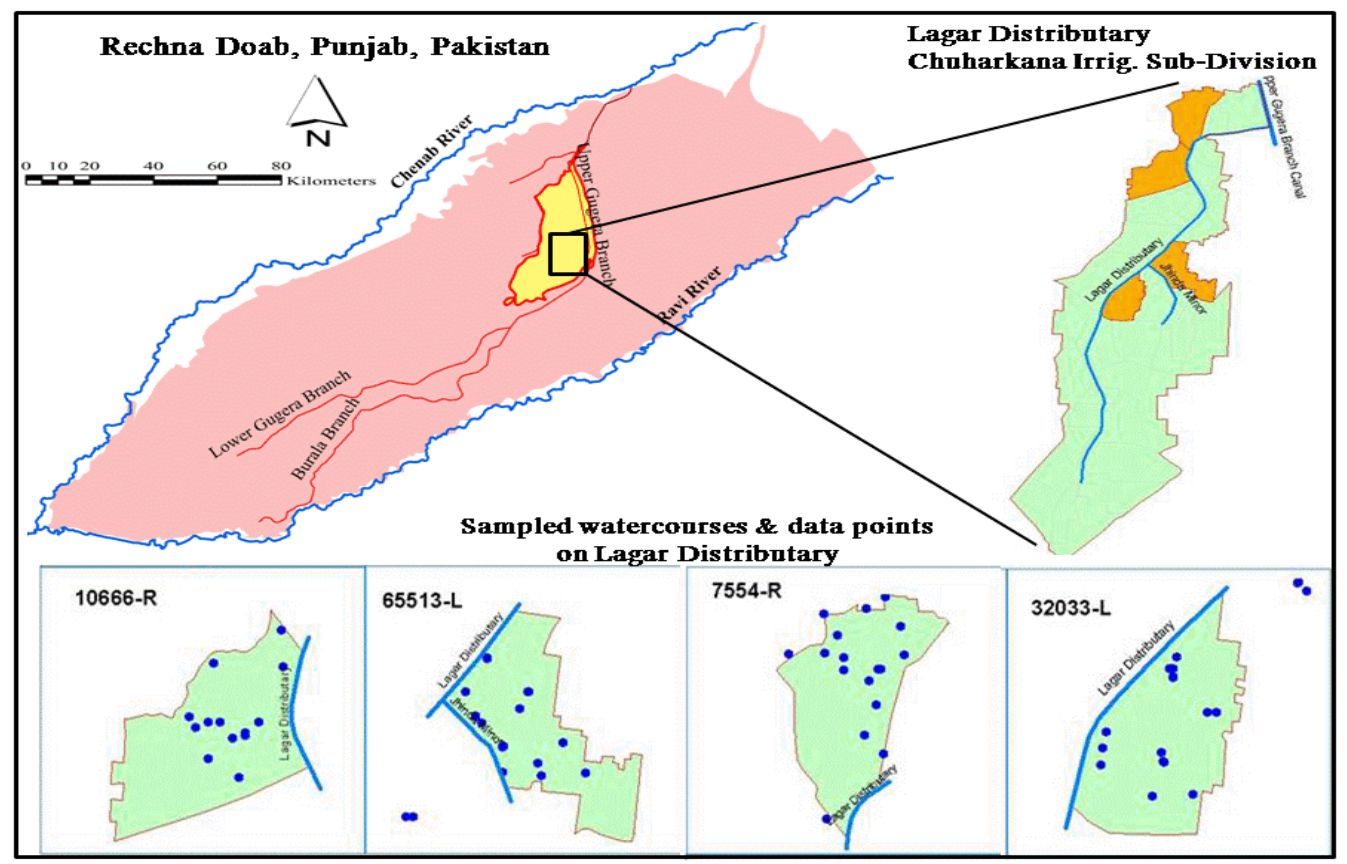

Figure 1. Geographical map of the study area showing sampled villages and data points for water samples (blue dots). 
Data collection and analysis: Two types of data were collected for this study, i.e. questionnaire-based information from farmers and data based on groundwater samples and tubewell discharge. Primary data for this study was collected for the cropping season 2009-10, for both Rabi and Kharif using a pre-tested questionnaire. The questionnaire used was of two types: (i) village questionnaire to collect general information about location, agricultural practices and irrigation management; (ii) farmer's questionnaire to collect data regarding respondents' socioeconomic attributes, cropping pattern, water and other inputs use for crop production.

Tubewell water samples were obtained from operational tubewells installed at different bore depths. Total number of water samples collected from tubewells was 60 as all the sampled farmers did not own their own tubewell. Collected water-samples were chemically examined to evaluate their quality and suitability for agricultural purposes. Trajectory method was employed to estimate the discharge from tubewells (Cunningham and Schalk, 2011).

Gross margins for wheat and rice were estimated to compare relative profitability of these two major crops in the study area. For estimation of gross margin, variable costs are deducted from gross income. Moreover, it does not include overhead costs such as rents, electricity, interest and insurance that are to be met irrespective of crop production. Average gross margin per ha for a specific crop was calculated by the following function (Hussain et al., 2003):

$$
G M_{i j}=\left(Y_{i j} \times P Y_{i j}\right)-\left(\sum_{m=1}^{n} C_{i j} \times P C_{i j}\right)
$$

Where: $\mathrm{GM}_{\mathrm{ij}}=$ Gross Margin from ' $\mathrm{i}^{\text {th' }}$ crop at ' $\mathrm{j}$ 'th' farm (' $\mathrm{i}$ ' represents wheat and rice while ' $\mathrm{j}$ ' $=1,2, . ., 120) ; \mathrm{Y}_{\mathrm{ij}}=$ Yield of ' $\mathrm{i}^{\text {th' }}$ crop at ' $\mathrm{j}$ ' ' farm; $\mathrm{PY} \mathrm{Y}_{\mathrm{ij}}=$ Price of ' $\mathrm{i}^{\text {th }}$ ' crop received by ' $\mathrm{j}$ th' farmer per $40 \mathrm{~kg} ; \mathrm{C}_{\mathrm{ij}}=$ Amount of variable inputs for ' $\mathrm{i}^{\text {th }}$ ' crop at ' $\mathrm{j}$ ' ' farm; $\mathrm{PC}_{\mathrm{ij}}=$ Price of variable inputs for ' $\mathrm{i}$ ' ' crop at ' $\mathrm{j}$ ' ' farm.

The collected data were analyzed using SPSS and MS-Excel. Standard statistical procedure was adopted to calculate percentages, means and ratios.

\section{RESULTS AND DISCUSSION}

First part of the results describes salient features of the study area including land and water resource situation. Second part mainly focuses on irrigated agriculture across different locations on watercourses. This follows the summary of key findings and conclusions.

Socio-physical Characteristics of the Study Area:

Land and water resources situation: Majority of the farmers of study area were small farmers (88\%) operating on less than 5 ha of land. The average farm size was 3.2 ha with 3.59 ha, 3.22 ha and 2.79 ha at head, middle and tail reaches of watercourses, respectively. Sandy loam was the major soil type followed by clay loam and loamy soils. Fine textured soil, i.e., clay loam was more prevalent at tail than at head and middle reaches of watercourses. The quality of groundwater varied at different watercourse reaches in terms of electrical conductivity $\left(\mathrm{EC}_{\mathrm{e}}\right)$, sodium adsorption ratio (SAR) and residual sodium carbonate (RSC). The values of these indicators are reported in Table 1.

Table 1. Average values of EC, SAR and RSC across water channel command.

\begin{tabular}{|c|c|c|c|}
\hline $\begin{array}{l}\text { Location on } \\
\text { water channel }\end{array}$ & $\begin{array}{c}\mathrm{EC} \\
\left(\mathrm{dS} \mathbf{~ m}^{-1}\right)\end{array}$ & $\begin{array}{c}\text { SAR } \\
\left(\mathrm{mmol} \mathrm{L}^{-1}\right)^{1 / 2} \\
\end{array}$ & $\begin{array}{c}\text { RSC } \\
\left(\mathrm{meL}^{-1}\right)\end{array}$ \\
\hline Head & $1.27(0.06)$ & $6.39(0.69)$ & $3.75(0.42)$ \\
\hline Middle & $1.40(0.04)$ & $9.04(0.54)$ & $3.51(0.42)$ \\
\hline Tail & $1.55(0.06)$ & $9.54(0.67)$ & $4.18(0.75)$ \\
\hline
\end{tabular}

Figures in parenthesis show standard error for 20 tubewell water samples at head, middle and tail of the water courses.

Results in Table 1 show that the average EC value ranged from $1.27 \mathrm{dS} \mathrm{m}^{-1}$ at head to $1.55 \mathrm{dS} \mathrm{m}^{-1}$ at tail. All collected water samples showed low to medium salinity. The average value of SAR varied from $6.39\left(\mathrm{mmol} \mathrm{L}^{-1}\right)^{1 / 2}$ at head to 9.54 at tail. The medium ranged values of SAR might be due to more sodium ions as compared to calcium and magnesium ions. The average value of RSC in water samples was 3.51 $\mathrm{meL}^{-1}$ at middle as compared to 3.75 and $4.18 \mathrm{meL}^{-1}$ at head and tail, respectively. Overall, higher average values of RSC were observed at tail as compared to head and middle. This high RSC is the main reason for poor water quality regardless of location along the water channel. Higher RSC values are the result of higher bicarbonate ions concentration for most of the cases. About 21\% tubewells at head were reported to pump good quality water as compared to none at the tail while about $79 \%$ tubewells pumped marginal to poor quality water at head. All the farmers at tail pumped marginal to poor quality water. Results also show that majority of tubewells in the study area pumped poor quality water. These results are consistent with findings of Kazmi et al. (2012) for canal command of Lagar distributary and Qureshi et al. (2002) in case of Rechna Doab.

Tubewell ownership and accessibility across location: Different types of tubewells are installed in the study area across various watercourse reaches. Results in Table 2 show that diesel-operated centrifugal pumps (61\%) dominated followed by electric centrifugal motors (34\%). Electricityoperated submersible motors and tractor-operated wells were equal in number, i.e. $5 \%$ each. The reason for higher percentage of diesel-operated pumps is their lower installation cost compared to the installation cost of electricity-operated centrifugal and submersible motors along with procedural and bureaucratic hurdles in securing electric connection (Mienzen-Dick, 1996; Kazmi and Ertsen, 2011). Frequent power breakdowns may also discourage farmers from switching to electric motors although their 
Usman, Abbas \& Saqib

Table 2. Type and ownership of tube-wells (in percentage) across different watercourse reaches in the study area.

\begin{tabular}{lccccccccc}
\hline $\begin{array}{l}\text { Type of } \\
\text { tubewells }\end{array}$ & \multicolumn{3}{c}{ Head } & \multicolumn{1}{c}{ Middle } & \multicolumn{3}{c}{ Tail } \\
\cline { 2 - 9 } & $\begin{array}{c}\text { Self- } \\
\text { Owned }\end{array}$ & Shared & Total & $\begin{array}{c}\text { Self- } \\
\text { Owned }\end{array}$ & Shared & Total & $\begin{array}{c}\text { Self- } \\
\text { Owned }\end{array}$ & Shared & Total \\
\hline $\begin{array}{l}\text { Diesel-operated } \\
\text { centrifugal pumps }\end{array}$ & 50.0 & 10.0 & 60.0 & 56.6 & 10.0 & 66.7 & 53.1 & 3.1 & 56.3 \\
$\begin{array}{l}\text { Electricity-operated } \\
\text { centrifugal pumps }\end{array}$ & 20.0 & 3.3 & 23.3 & 23.3 & 3.3 & 26.7 & 18.7 & 15.7 & 34.4 \\
$\begin{array}{l}\text { Electricity-operated } \\
\text { submersible pumps }\end{array}$ & 6.7 & 0.0 & 6.7 & 3.3 & 0.0 & 3.3 & 3.1 & 3.1 & 6.2 \\
$\begin{array}{l}\text { Tractor-operated wells } \\
\text { Total number of TWs }\end{array}$ & 6.7 & 3.3 & 10.0 & 3.3 & 0.0 & 3.3 & 0.0 & 3.1 & 3.1 \\
\hline
\end{tabular}

operational costs are relatively low than that of dieseloperated pumps. The number of tubewells at watercourse tails was slightly higher than at the middle and head due to reduced availability of canal water there which has implications of extensive groundwater extraction and water depletion in future. Most tubewells were self-owned while the proportion of shared tubewells was relatively high at tail. Higher installation cost associated with electric tubewells might be driving force for tubewell sharing among farmers along with smaller size of land holdings at tail making it uneconomical to install own tubewells.

The installation of private tubewells in Punjab is on the rise as well as in the study area. The literature also supports that the province has shown substantial increase in the number of private tubewells (Kazmi and Ertsen, 2011; Laghari et al., 2012). These wells are drilled to various depths depending on the groundwater table. Most of the tubewells were installed at shallow depths (up to $38 \mathrm{~m}$ ) at head and middle reaches of watercourse due to higher water table beneath the surface. A significant proportion of deep tubewells (>45 m) was at the tail. Pumping water from deeper layers not only increases the cost of tubewells installation and water pumping but also poses a greater risk of soil salinity through saline water intrusion into the fresh water aquifer. This fact is evident from the relatively high values of EC, SAR and RSC at tails (Table 1). These results conform to the findings of PERI (2007) who state that high-energy cost, declining groundwater tables and incipient secondary salinization are major threats to the sustainability of groundwater economy. Results of this study also showed that there was no difference in water discharge along the head, middle and tail reaches of watercourse given the types of tubewells.

Irrigated Agriculture in the Study Area:

Modes of irrigation: Most of the studied farm area is irrigated by ground and canal water as shown in Fig. 2. On overall basis, area irrigated by conjunctive use was the highest across all locations, followed by groundwater alone. These results indicate larger share of groundwater in irrigation water supplies for crop production at farm level. Results reveal that more than $52 \%$ farmers irrigate $61 \%$ of the cropped area by conjunctive use of surface and groundwater. However, the area irrigated by both sources decreased from $76.6 \%$ at head to around $46 \%$ at tail thus indicating a declining canal water supply along tail reaches. Moreover, the percentage of farmers practicing conjunctive use of water also decreased from $61.6 \%$ at head to $43.7 \%$ at tail while this percentage increased from $33 \%$ at head to $56 \%$ at tail in case of only groundwater application. Area irrigated by tubewells alone was much higher, i.e. $38.5 \%$ of the cultivated area. Average area irrigated by canal water alone was very small (less than 1\%) decreasing from head to tail significantly. These results are suggestive of overreliance on groundwater for crop production. Previous results support these findings, for example, Qureshi et al. (2009) have reported an increase from $2.7 \mathrm{mha}$ to $3.4 \mathrm{mha}$ in area irrigated by groundwater alone while a reduction in canal-irrigated area from 7.9 mha to 6.9 mha. On the other hand, severe depletion of groundwater resources is observed especially in Punjab where its abstraction has exceeded rate of recharge (Archer et al., 2010).

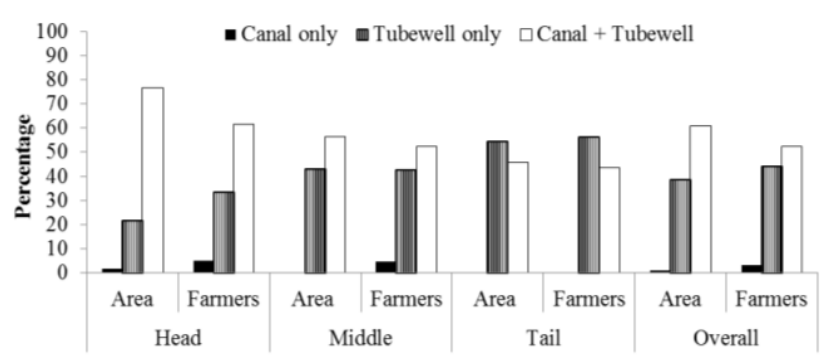

Figure 2. Percent farm area irrigated by various sources and percentage of the farmers using these sources along watercourse reaches.

Cropping pattern and cropping intensity: Rice and wheat are the dominant crops grown in the study area with wheat occupying more than $75 \%$ cultivated area during Rabi season for all watercourse reaches $(78 \%, 77 \%$ and $81 \%$ at head, middle and tail, respectively) whereas rice occupied more than $50 \%$ area at head and middle reaches $(56 \%$ and 
$53 \%$, respectively) during Kharif. Rice area increased towards the tail $(70 \%$ of the cultivated area) due mainly to the presence of fine textured soils

Fig. 3 portrays the cropping intensity in the study area with respect to location of the sampled watercourses. There is not much variation in both seasonal and annual cropping intensities across the channel reaches. The area is intensively cultivated as the average cropping intensity was more than $190 \%$. The intensive cultivation pattern followed in the study area shows excessive reliance on groundwater and its abstraction as the present canal irrigation system was designed for a cropping intensity of about $75 \%$. Reported variation in annual cropping intensity across canal commanded area of Punjab also ranges from $60 \%$ to $192 \%$ (Qureshi et al., 2004; Kazmi et al., 2012). Reason for higher cropping intensities in the study area was the cultivation of sesame crop during Kharif season instead of leaving land fallow.

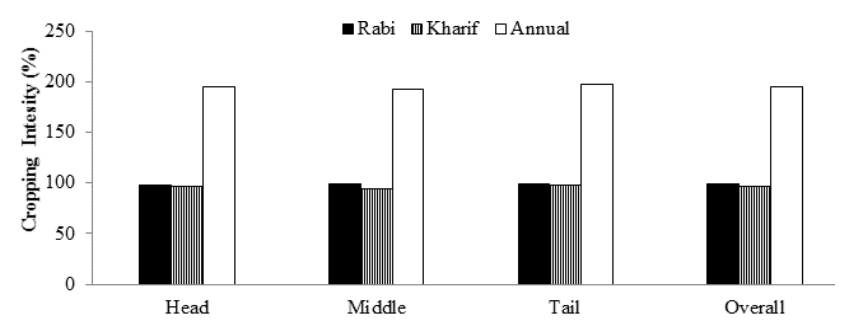

Figure 3. Seasonal and annual cropping intensities in the study area along watercourse reaches.

Water input use level: Rice is the most frequently irrigated crop in the study area as average number of irrigations ranged between 33-38 followed by sugarcane and wheat with their respective ranges of 25-32 and 4-5. Generally, in Punjab, 15-25 irrigations are applied to rice from its transplantation till maturity (Ahmad et al., 2007) but due to the prevalence of coarse textured soils in the study area, rice is irrigated even more frequently. This finding implies discouraging rice cultivation in coarse textured soils. Average number of irrigations applied to wheat remained almost constant across water channel reaches. Moreover, farther the farm from head of the watercourse, smaller the share of canal water and larger the share of groundwater were. The increase in groundwater application away from head is mainly due to reduced availability of canal water resulting from conveyance losses in poorly managed water courses, evapotranspiration and water theft (Baig, 2008).

Heavy reliance on groundwater can be seen from Table 3. The average amount of groundwater applied to wheat crop ranged from $3390 \mathrm{~m}^{3} \mathrm{ha}^{-1}$ to $4002 \mathrm{~m}^{3} \mathrm{ha}^{-1}$ with overall average being $3625 \mathrm{~m}^{3} \mathrm{ha}^{-1}$. Rice was the major consumer of groundwater as its average consumption per hectare ranged from $25504 \mathrm{~m}^{3}$ to $26658 \mathrm{~m}^{3}$. Such a high amount of water applied to rice may also intensify the problem of salinity and water-logging (Ashraf et al., 2014). Groundwater irrigation alone surpasses the crop water requirement in many cases. If canal water is also taken into account, both wheat and rice are heavily over-irrigated in the study area. This practice may result into increased production cost, rapid groundwater depletion, poor soil health and environmental degradation.

Table 3. Groundwater usage by major crops across watercourse reaches.

\begin{tabular}{lrrrr}
\hline Crop & \multicolumn{4}{c}{ Groundwater use $\left(\mathbf{m}^{\mathbf{3}} \mathbf{h a}^{\mathbf{- 1}}\right)$} \\
\cline { 2 - 5 } & Head & Middle & \multicolumn{1}{c}{ Tail } & Overall \\
\hline Wheat & 3390 & 3553 & 4002 & 3625 \\
Rice & 25504 & 25526 & 26658 & 25986 \\
Sugarcane & 7440 & 12070 & 28463 & 16609 \\
Total & 36334 & 41149 & 59123 & 46220 \\
\hline
\end{tabular}

Crop and Groundwater productivity: Average yields of major crops are presented in Table 4. The yields of wheat and rice crops at tail reaches were respectively $7.2 \%$ and $16 \%$ higher than at head due to improved soil conditions besides better agronomic practices. Average wheat yield varied between 3.3 to $3.5 \mathrm{t} \mathrm{ha}^{-1}$ and that of rice ranged between 3.6 to $3.7 \mathrm{t} \mathrm{ha}^{-1}$ alongside the head to tail reaches of watercourses. Similar yield values are reported by Usman et al. (2014) for rice and wheat in Rechna Doab of Punjab.

Table 4. Crop yields $\left(\mathrm{t} \mathrm{ha}^{-1}\right)$ along watercourse reaches in the study area.

\begin{tabular}{lccc}
\hline Location & Wheat & Rice & Sugarcane \\
\hline Head & 3.3 & 3.6 & 63.3 \\
Middle & 3.4 & 3.4 & 51.7 \\
Tail & 3.5 & 3.7 & 57.3 \\
Overall & 3.4 & 3.6 & 58.3 \\
\hline
\end{tabular}

The groundwater productivity of all crops decreased from head to tail except for rice which is slightly higher at tail. Considering crop output per $\mathrm{m}^{3}$ of water, there is not a significant difference in case of wheat and rice while there is significant difference in case of sugarcane from head to tail as shown in Table 5. Groundwater productivity in case of sugarcane was the highest at the head mainly due to higher yields and less groundwater application. Usman et al. (2014) have reported crop water productivity values of 0.14 to 0.56 and 0.54 to $1.44 \mathrm{~kg} \mathrm{~m}^{-3}$ for rice and wheat, respectively in the Rechna doab, which are quite comparable to present study.

Table 5. Groundwater productivity $\left(\mathrm{kg} \mathrm{m}^{-3}\right)$ of major crops along different watercourse reaches.

\begin{tabular}{lccc}
\hline Location & Wheat & Rice & Sugarcane \\
\hline Head & 0.97 & 0.14 & 8.50 \\
Middle & 0.96 & 0.13 & 4.28 \\
Tail & 0.89 & 0.14 & 2.01 \\
Overall & 0.94 & 0.14 & 3.51 \\
\hline
\end{tabular}


Other crop inputs use: Values in Table 6 depict that ploughing and planking are applied in higher number on farms across head and less across tail of watercourse. Overall use of ploughing and planking is higher in preparing land for wheat compared to rice. Average net application of nitrogen $(\mathrm{N})$ and phosphorus $(\mathrm{P})$ shows increasing trend from head to tail for rice and wheat. Highest dose of $\mathrm{N}$ (109.18 $\mathrm{kg} \mathrm{ha}^{-1}$ ) was applied to wheat at tail, while highest dose of P (70.96 $\left.\mathrm{kg} \mathrm{ha}^{-1}\right)$ was applied to rice at tail. The use of both nutrients ( $\mathrm{N}$ and $\mathrm{P}$ ) was higher for wheat and rice at tail. There was no difference in hired labor use, being used during peak work load, i.e., harvesting and threshing by all farmers regardless of location.

Profitability of wheat and rice production: As wheat and rice constitute the major crops in the study area, their profitability in terms of gross margins were evaluated in order to know their variation along watercourse reaches. Total value product (TVP), cost of production, gross margins and ratio of gross margins to cost of production are presented in Table 7. The results show that overall TVP of wheat and rice was Rs. 82273 and Rs. 112194 per ha, respectively. TVP of wheat and rice was the highest at tail. Overall cost of production for wheat and rice was Rs. 35847 and Rs. 53799 per ha, respectively. Cost of Fertilizer was major component in cost of production for wheat followed by land preparation, harvesting and irrigation while in case of rice; irrigation cost was the major component, fertilizer application and land preparation being the other major ones. Overall cost of production was relatively less at tail. The number of electric tubewells was higher at tail compared to other locations while per hour operational cost of electric tubewell was almost half of the cost of diesel-operated tubewells. It could be the cause of lower cost of production besides lower harvesting and land preparation costs at tail. Overall gross margin for wheat and rice was Rs. 46426 and Rs. 58395 per ha, respectively. The gross margin was relatively higher at tail for both crops as was the ratio of gross margin to the cost of production mainly due to relatively lower variable cost. On overall basis, the ratio of gross margin to the cost of production for wheat was 1.29 and 1.09 for rice.

These findings indicate that farmers at the tail were obtaining $10-17 \%$ and $14-31 \%$ more gross profits respectively per ha of wheat and rice compared with the farmers at head and middle of the watercourse reaches. Reasons for more profitable crop production may include favorable soil conditions (presence of fine textured soils), flexibility and control in regulating water supply through groundwater. Moreover, the cost of production at tail reaches was also somewhat lowered due to reduced costs on cultural practices. These results indicate a higher economic benefit to the tail farmers mainly due to flexibility in terms of irrigation planning and control, especially for rice which consumes excessive amount of water. On the other hand, as shown in Table 5, groundwater productivity declines towards the tail reaches. Although increased profitability is the result of combine role of all inputs but role of better soil conditions cannot be over-ruled. Hence the farmers are tempted to use relatively cheaper groundwater resource in higher proportion. This outcome warrants a policy intervention or at least extension guidelines to conserve groundwater through its judicious use along with halting soil degradation through salt deposition.

Table 6. Location-wise inputs use per ha for wheat and rice crops.

\begin{tabular}{lcccrrr}
\hline Input Items & \multicolumn{2}{c}{ Head } & \multicolumn{2}{c}{ Middle } & \multicolumn{2}{c}{ Tail } \\
\cline { 2 - 6 } & Wheat & Rice & Wheat & Rice & Wheat & Rice \\
\hline Ploughings (No.) & 5.00 & 3.63 & 4.75 & 3.39 & 4.40 & 3.70 \\
Plankings (No.) & 2.70 & 2.12 & 3.20 & 2.48 & 2.66 & -54 \\
Puddlings (No.) & - & 1.86 & - & 1.68 & 1.78 & 122.19 \\
Seed rate (kg) & 119.82 & 9.11 & 121.87 & 9.61 & 52.60 & 61.70 \\
FYM (tons) & 47.00 & 68.00 & 49.40 & 52.80 & 109.18 & 108.24 \\
N (kg) & 82.17 & 80.93 & 84.92 & 87.38 & 69.27 & 70.96 \\
P (kg) & 62.55 & 56.16 & 66.63 & 62.74 & 31.00 & 29.00 \\
Hired Labour (Days) & 29.00 & 35.00 & 32.00 & 25.00 & \\
\hline
\end{tabular}

Table 7. Profitability of wheat and rice crops across three watercourse reaches (Rs/ha).

\begin{tabular}{|c|c|c|c|c|c|c|c|c|}
\hline \multirow{2}{*}{$\begin{array}{l}\text { Location } \\
\text { Profitability }\end{array}$} & \multicolumn{4}{|c|}{ Wheat } & \multicolumn{4}{|c|}{ Rice } \\
\hline & Head & Middle & Tail & Overall & Head & Middle & Tail & Overall \\
\hline Yield $\left(\mathrm{t} \mathrm{ha}^{-1}\right)$ & 3.33 & 3.42 & 3.56 & 3.44 & 3.54 & 3.42 & 3.75 & 3.55 \\
\hline Total Value Product (TVP)* & 80361 & 81349 & 85111 & 82273 & 111814 & 106521 & 118251 & 112194 \\
\hline Cost of Production (CoP) & 37279 & 35501 & 34765 & 35847 & 54352 & 55654 & 51388 & 53799 \\
\hline Gross Margin (GM) & 43082 & 45848 & 50346 & 46426 & 57462 & 50867 & 66863 & 58395 \\
\hline Ratio of GM to CoP & $1 . .15$ & 1.29 & 1.44 & 1.29 & 1.06 & 0.91 & 1.30 & 1.09 \\
\hline
\end{tabular}

*Using support price of wheat and rice @ Rs. 950 and Rs. 1250 per $40 \mathrm{~kg}$, respectively. 
Conclusions: This study was conducted in rice wheat system of Punjab, Pakistan. The trend of using canal water and groundwater is on the rise. Most of the tubewells were pumping poor quality water from deeper layers of aquifer. The use of groundwater increased from head to tail to the tune of $38 \%$ for whole sampled farms. On an overall basis, irrigated area under conjunctive water use was the highest, followed by groundwater and canal only. Farmers at the head reaches preferred to dig shallow-depth tubewells while most farmers towards tail reaches dig their tubewells to deeper layers. The use of electricity-operated tubewells was more at tail. Wheat and rice yields per hectare were higher at tail as compared to head resulting in higher TVPs at tail mainly due to good quality soils. Among major crops, rice has the highest profitability followed by wheat. Gross margins and cost benefit ratios were slightly higher at tail as compared to head and middle. Although groundwater productivity per unit of water gradually lowered from head to tail, however, easy access to groundwater and better irrigation planning by the farmers towards tail-ends increased the crop yields and resultant profitability. Nevertheless, the continuous and excessive application of groundwater with increased amount of salts may lead to the deterioration of soil conditions in the long-run. The presence of relatively more amounts of soluble salts in the tubewell water is one such factor which can lead to heavy salt deposition on soil surface thus causing negative consequences in the future. To avoid this to happen, implementation of existing regulations or enacting new ones are required to ensure effective groundwater management. This is necessary intervention as overexploitation of groundwater by private users would have implications in terms of resource and quality deterioration even for domestic purposes. Similarly, societal awareness and logical motivation among farming community can bridge this gap as well; such as encouraging upstream farmers to wisely use groundwater while providing more canal water to tail-end farmers to avoid soil salinization and production losses. The dissemination of proper mixing ratios of surface and groundwater to farming community and pursuing them to use groundwater for high-valued crops instead of traditional crops can potentially be helpful in addressing the issue of soil degradation along with improving farm income.

\section{REFERENCES}

Ahmad, M.D., H. Turral, I. Masih, M. Giordano and Z. Masood. 2007. Water saving technologies: Myths and realities revealed in Pakistan's rice-wheat systems. Colombo, Sri Lanka: International Water Management Institute (IWMI) Research Report No. 108:44.

Ahmad, S. 2007. Land and water resources of Pakistan-a critical assessment. Pak. Dev. Rev. 46:911-937.
Archer, D.R., N. Forsythe, H.J. Fowler and S.M. Shah. 2010. Sustainability of water resources management in the Indus Basin under changing climatic and socio economic conditions. Hydrol. Earth Syst. Sci. 14:16691680.

Ashraf, M., M.K. Marri, I. Rao, A. Salam and M.A. Khan. 2014. Pancho-irrigation system- A wasteful practice of irrigating rice fields in the lower Indus Basin of Pakistan. Pak. J. Agri. Sci. 51:867-873.

Baig, I.A. 2008. An economics analysis of irrigation changes and cost recovery under reforms environment: A case study of Punjab. Ph.D Disst., Dept. Agri. Econ., University of Agriculture, Faisalabad, Pakistan.

Bureau of Statistics. 2013. Punjab Development Statistics 2013. Govt. of Punjab, Pakistan.

Cunningham, W.L. and C.W. Schalk. 2011. Groundwater technical procedures of the U.S. geological survey. US Geological Survey Techniques and Methods 1-A1, US Geological Survey, Reston,VA.

Evans, W.R. and R. Evans. 2011. Conjunctive use and management of groundwater and surface water. Groundwater Governance- A global framework for action, Rome, Italy. Thematic Paper No. 2, p. 26.

Hussain, I., R. Sakthivadive and H. Amarasinghe. 2003. Land and water productivity of wheat in the Western Indo Gangetic Plains of India and Pakistan: A comparative analysis, pp.255-271. In: J.W. Kijne, R. Barker and D. Molden (ed.), Water Productivity in Agriculture: Limits and opportunity for improvement. CABI Publishing, Cambridge MA, USA.

Kazi, A. 2014. A review of the assessment and mitigation of floods in Sindh, Pakistan. Natural Hazards 70:839-864.

Kazmi, S.I., M.W. Ertsen and M.R. Asi. 2012. The impact of conjunctive use of canal and tube well water in Lagar irrigated area, Pakistan. Phy. Chem. Earth 47-48:86-98.

Kazmi, S.I.H.S. and M.W. Ertsen. 2011. Changes in tube wells count in two decades in area under conjunctive irrigation in Pakistan, pp.1-13. Proceedings of the $25^{\text {th }}$ ICID European Regional Conference. 16-20 May 2011, Groningen, the Netherlands. Available online at http://repository.tudelft.nl/assets/uuid:e4167514-4ceb4e4f-8abb-bf6da201d16f/Paper_IV-17_Ertsen_et_al.pdf

Laghari, A.N., D. Vanham and W. Rauch. 2012. The Indus basin in the framework of current and future water resources management. Hydrol. Earth Syst. Sci. 16:1063-1083.

Meinzen-Dick, R. 1996. Groundwater markets in Pakistan: Participation and productivity. International Food Policy Research Institute, Research Report 105. Washington DC; p.76.

PERI, 2007. Punjab Economic Report. Punjab Economic Research Institute, Govt. of Punjab, Lahore, Pakistan. 
Qureshi, A.S., P.G. McCornick, A. Sarwar and B.R. Sharma. 2009. Challenges and prospects of sustainable groundwater management in the Indus Basin, Pakistan. Water Resour. Manage. 24:1551-1569.

Qureshi, A.S., A. Hussain and I. Makin. 2002. Integrated database development for river basin management: An example from Rechna Doab. Working paper 53, International Water Management Institute (IWMI), Lahore, Pakistan.

Qureshi, A.S., H. Turral, and I. Masih. 2004. Strategies for the management of conjunctive use of surface water and groundwater resources in semi-arid areas: A case study from Pakistan. IWMI Research Report No. 86. Colombo, Sri Lanka.

Qureshi, A.S., P.G. McCornick, M. Qadir, and Z. Aslam. 2008. Managing salinity and water logging in the Indus Basin of Pakistan. Agr. Water Manag. 95:1-10.

Raza, M.A., M. Ashfaq, S.H. Abidi and A. Ali. 2010. Change in management of irrigation sector of Punjab (Pakistan) and its impact on income of wheat growers. Pak. J. Agri. Sci. 47:399-403.

Shabbir, A., M. Arshad, A. Bakhsh, M. Usman, A. Shakoor, I. Ahmad and A. Ahmad. 2012. Apparent and real water productivity for cotton-wheat zone of Punjab, Pakistan. Pak. J. Agri. Sci. 49:357-363.

Tularam, G.A. and P. Marchisella. 2014. Water scarcity in Asia and its long-term water and border security implications for Australia, pp.189-212. In: R.M. Clark and S. Hakim (ed.), Securing Water and Wastewater Systems: Global experiences. Springer International Publishing Switzerland.

Usman, M., R. Liedl, A.R. Kavousi. 2015. Estimation of distributed seasonal net recharge by modern satellite data in irrigated agricultural regions of Pakistan. Environmental Earth Sciences. http://doi.org/10.1007/ s12665-015-4139-7.

Usman, M., R. Liedl and M.A. Shahid. 2014. Managing irrigation water by yield and water productivity assessment of a rice-wheat system using remote sensing. J. Irrig. Drain. Engg. 140:1-11.

World Bank. 2006. Conjunctive use of groundwater and surface water. Agricultural and rural development notes, Issue 6.

World Bank. 2007. Punjab groundwater policy Mission report. WB-SA-PK Punjab GW Mission report, June 2007. Available online at http://www.worldbank.org/ gwmate 